\title{
To Study the Effect on Central Foveal Thickness Following Prompt/Deferred Macular Photocoagulation After Single Intravitreal Bevacizumab Injection
}

\author{
Aashka Shah, Vidhi Solanki* and Dipal Patel \\ Department of Ophthalmology, Gujarat University, India \\ *Corresponding Author: Department of Ophthalmology, Gujarat University, India
}

Received: September 23, 2020

Published: October 16, 2020

(C) All rights are reserved by Vidhi Solanki., et al.

\begin{abstract}
Aim: To find out the efficacy of macular photocoagulation when given in the early or late period after single intravitreal bevacizumab injection in terms of central foveal thickness change and visual acuity gain.

Methods: 40 patient eyes were studied and they were divided into groups based on sex, age, hba1c levels, severity of disease and treatment received over the period of 6 months.

Result and Conclusion: Patients receiving deferred macular photocoagulation after a single intravitreal injection of bevacizumab had better outcomes regarding reduction of central foveal thickness and improvement in visual acuity at the end of 6 month observation period compared to those patients receiving prompt macular photocoagulation.

Keywords: Bevacizumab; Laser Photocoagulation; Diabetic Retinopathy; Central Foveal Thickness; Clinically Significant Macular Edema
\end{abstract}

\section{Introduction}

Diabetic retinopathy is an ocular manifestation of diabetes mellitus, a systemic disease, which affects up to 80 percent of all patients who have had diabetes for 10 years or more [1].

Diabetic retinopathy (DR) is one of the leading causes of severe visual impairment. Diabetic retinopathy is the result of microvascular retinal changes. Hyperglycemia -induced intramural pericyte death and thickening of the basement membrane lead to incompetence of the vascular walls. These damages change the formation of the blood-retinal barrier and also make the retinal blood vessels become more permeable.

Diabetic retinopathy can be classified as:

- $\quad$ Non-proliferative diabetic retinopathy

- Proliferative diabetic retinopathy

- Diabetic Maculopathy.
CSME as described by the Early Treatment of Diabetic Retinopathy Study occurring in Diabetic Retinopathy is defined as:

\section{Clinically Significant Macular Edema} (ETDRS)

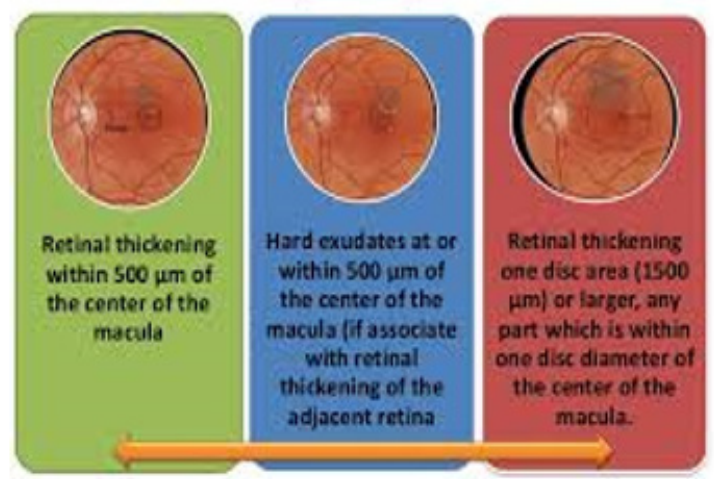

Figure 1 
Routine investigations includes diabetes profile, haemoglobin, urine albumin, lipid profile and renal function test.

Imaging

- Indirect ophthalmoscopy

- Fundus photography

- $\quad$ Optical coherence tomography (OCT)

- $\quad$ Fundus fluorescein angiography (FFA).

\section{Management}

- Laser photocoagulation

- Medical treatment.

Intravitreal anti-vascular endothelial growth factor

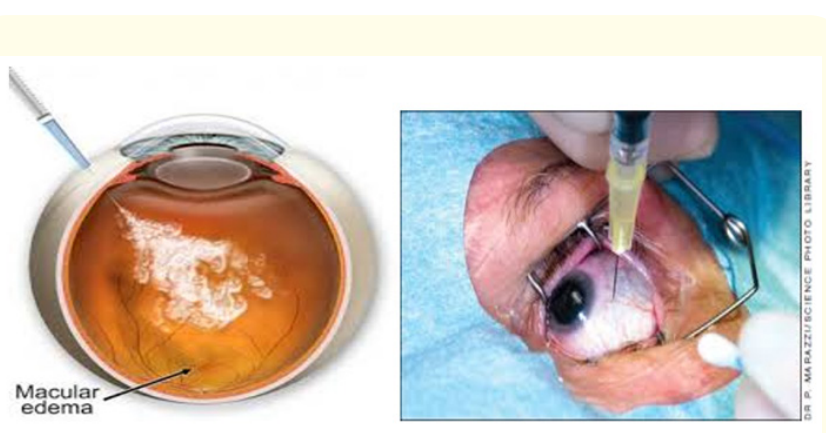

Figure 2

\section{Bevacizumab}

It is a full-length, recombinant, humanized antibody active against all isoforms of VEGF-A. Several studies reported the use of the off-label intravitreal injection of bevacizumab to treat DME and PDR. The commonly used typical dose is $1.25 \mathrm{mg}$, although doses as low as $6.2 \mu \mathrm{g}$ and as high as $2.5 \mathrm{mg}$ have been used.

\section{Aims of Study}

To find out the efficacy of macular photocoagulation when given in the early or late period after single intravitreal bevacizumab injection in terms of central foveal thickness change and visual acuity gain.

\section{Materials and Methods}

40 eyes have been included in the study.

Inclusion criteria

- $\quad$ Age $\geq 40$ years

- $\quad$ Type 2 diabetes
- $\quad$ DME which is diagnosed as diffuse DME on fundus fluorescein angiography.

- Visual acuity (EDTRS charting) 20/320 or better.

\section{Exclusion criteria}

- $\quad$ Systemic

- $\quad$ Significant renal disease

- Uncontrolled diabetes

- $\quad$ BP > 180/110 mm hg

- $\quad$ Cardiac event or stroke within 4 months

- $\quad$ Study eye

- Prior MPC

- Tractional retinal detachment involving the macula

- $\quad$ NV of the angle

- $\quad$ History of intravitreal anti-VEGF within past 2 months

- History of corticosteroid in the past 4 months.

\section{Baseline evaluation}

All patients had a complete pre-treatment evaluation with detailed history.

\section{Blood investigations}

All patients were asked for routine blood investigations which included total blood count, fasting and post prandial blood sugar, $\mathrm{HbA1c}$, renal function tests, serum lipid profile and urine routine examination.

\section{Ophthalmic examination}

Detailed ophthalmic history including history of glasses, any eye trauma or surgery, previous any lasers or intravitreal injections taken before recorded. Detailed ophthalmic examination was done including best corrected refraction, best-corrected visual acuity (BCVA) testing objective/subjective refraction using retro illuminated SNELLENS chart, classification of lenticular status and Applanation tonometry and the complete retinal assessment was done.

Treatment protocol

- $\quad$ Group 1 (20 EYES): Receiving prompt treatment in the form of photocoagulation within a week after single intravitreal bevacizumab injection. 
To Study the Effect on Central Foveal Thickness Following Prompt/Deferred Macular Photocoagulation After Single Intravitreal Bevacizumab Injection

- $\quad$ Group 2 (20 EYES): Receiving deferred treatment in the form of photocoagulation after receiving intravitreal Bevacizumab in the dose of $1.25 \mathrm{mg} / 0.05 \mathrm{ml}$ in one month.

\section{Method of intravitreal bevacizumab}

After explaining procedure and taking written consent patient had been taken to operation theatre. After full pupillary dilation topical anaesthesia in the form of $4 \%$ lignocaine is applied in conjunctival cul-de-sac. $5 \%$ povidone iodide on to the ocular surface is applied and allowed for adequate time ( 3 minutes) prior to injection as aseptic precaution. $1.25 \mathrm{mg}$ bevaciumab is prepared in $0.05 \mathrm{ml}$ of tuberculine syringe with 27 gauge needle. Periocular area is cleaned with $5-10 \%$ povidone iodine. After applying sterile drape and adjusting microscope patient is asked to fixate in gaze away from the site of injection. Mark the scleral injection site using the mm gauge (the entry site of the needle should be $3.0-3.5 \mathrm{~mm}$ from the limbus in aphakic/pseudophakic patients, and $4.0 \mathrm{~mm}$ in phakic patients). Using forceps to steady the eye (if necessary), the needle is inserted perpendicular through sclera with the tip aimed towards the centre of the globe (to avoid any contact with the posterior lens). $0.1 \mathrm{ml}$ of therapeutic agent injected slowly and carefully.

\section{Method of grid/focal laser}

Focal macular treatment includes focal laser treatment of microaneurysms and grid treatment of areas of diffuse leakage and focal nonperfusion within 2DD of center of the macula. Spot size: 50-100 micron is utilized. The burn intensity for grid laser = barely visible (light gray). Power of laser burn is between $120-150 \mathrm{~mW}$ depending on the condition of the laser, the opacities in the media and background pigmentation. Laser burns should be placed at least one burn width apart -- wider if thickening is less severe. If necessary, the grid can extend up to 2 disc diameters superiorly, inferiorly, and temporally from the centre of the macula. One should avoid treating within 500 microns of the disc margin or the centre of the macula. Duration of about $0.05-0.1 \mathrm{sec}$ is used. Number of spots- $100-500$.

\section{Follow-up schedule}

Following parameters are checked for on follow-up visits postinjection.

\begin{tabular}{|l|c|c|c|c|c|}
\hline & $\begin{array}{c}\mathbf{1}^{\text {st }} \\
\text { Day }\end{array}$ & $\begin{array}{c}\mathbf{1}^{\text {ST }} \\
\text { Week }\end{array}$ & $\begin{array}{c}\mathbf{1}^{\text {ST }} \\
\text { Month }\end{array}$ & $\begin{array}{c}3^{\text {RD }} \\
\text { Month }\end{array}$ & $\begin{array}{c}\mathbf{6}^{\mathrm{TH}} \\
\text { Month }^{\text {Mont }}\end{array}$ \\
\hline Visual Acuity & & & & & \\
\hline IOP & & & & & \\
\hline CFT & & & & \\
\hline Clinical Findings & & & & & \\
\hline
\end{tabular}

Table 1
Data analysis

Out of the 40 patients studied 26 were males (65\%) and 14 (35\%) were females.

Age wise distribution

\begin{tabular}{|c|c|c|}
\hline Age (in years) & Number of patients & Percentage (\%) \\
\hline $40-50$ & 7 & 17.5 \\
\hline $51-60$ & 21 & 52.5 \\
\hline $61-70$ & 10 & 25 \\
\hline$>70$ & 2 & 5 \\
\hline
\end{tabular}

Table 2

Mean age being: 56.2 years.

Maximum number of patients having diabetic retinopathy fall into the age group of 50 - 60 years.

As described in our study $62.5 \%$ of the patients received prompt photocoagulation (within 1 week) after single intravitreal bevacizumab injection and $37.5 \%$ of the patients received deferred photocoagulation ( $>1$ week and $<1$ month).

The severity of diabetic retinopathy in the patients presented to our tertiary eye care hospital.

\begin{tabular}{|l|c|c|}
\hline Severity of diabetes & Number of patients & Percentage (\%) \\
\hline Mild NPDR with DME & 3 & 7.5 \\
\hline $\begin{array}{l}\text { Moderate NPDR with } \\
\text { DME }\end{array}$ & 17 & 42.5 \\
\hline $\begin{array}{l}\text { Severe NPDR with } \\
\text { DME }\end{array}$ & 20 & 50 \\
\hline
\end{tabular}

Table 3

\begin{tabular}{|c|c|}
\hline Group A & IV A + Prompt mpc \\
\hline Group B & IV A + Deferred mpc \\
\hline
\end{tabular}

Table 4

The above table shows the distribution of patients in the 2 groups of treatment.

Sex wise distribution

\begin{tabular}{|l|c|c|c|c|}
\hline & Group a & $\begin{array}{c}\text { Percentage } \\
\text { (\%) }\end{array}$ & Group b & $\begin{array}{c}\text { Percentage } \\
\text { (\%) }\end{array}$ \\
\hline Males & 16 & 64 & 10 & 66.7 \\
\hline Females & 9 & 36 & 5 & 33.3 \\
\hline Total & 25 & 100 & 15 & 100 \\
\hline
\end{tabular}

Table 5 


\section{Distribution according to HbA1c levels}

According to the guidelines a HbA1c value of $<=7$ is considered to be as good glycemic control of past 3 months whereas values above 8.0 indicates poor glycemic control.

\begin{tabular}{|c|c|c|}
\hline HbA1c Levels & Group A & Group B \\
\hline$<7.0$ & 4 & 3 \\
\hline $7.0-8.0$ & 8 & 10 \\
\hline$>8.0$ & 3 & 2 \\
\hline Total & 25 & 15 \\
\hline
\end{tabular}

Table 6

Analysis and Results
- $\quad$ Statistical analysis was done using Graph Pad InStat-3 software.

- Comparison between pre-intervention and post-intervention values in individual groups was analysed using PAIRED T TEST (in data following normal distribution) and Wilcoxon Matched Pairs Test (in data not following normal distribution).

- While comparison between the groups for all variables was done using Unpaired T Test Welch Corrected (in data following normal distribution) and Mann Whitney Test (in data not following normal distribution).

- A "p" value $\leq 0.05$ was considered statistically significant.

- Data tabulation was performed on Microsoft-excel worksheets.

\begin{tabular}{|c|c|c|c|c|c|c|c|c|}
\hline CFT & \multicolumn{8}{|c|}{ Number of Patients } \\
\hline \multirow[b]{2}{*}{ (In Microns) } & \multicolumn{4}{|c|}{ Group A (IV A + Prompt MPC) } & \multicolumn{4}{|c|}{ Group B (IV A + Deferred MPC) } \\
\hline & $\begin{array}{c}\text { Pre-treat- } \\
\text { ment }\end{array}$ & $\begin{array}{c}1^{\text {st }} \\
\text { month }\end{array}$ & $\begin{array}{c}3^{\text {rd }} \\
\text { month }\end{array}$ & $\begin{array}{c}6^{\text {th }} \\
\text { month }\end{array}$ & $\begin{array}{c}\text { Pre-treat- } \\
\text { ment }\end{array}$ & $\begin{array}{c}1^{\text {st }} \\
\text { month }\end{array}$ & $3^{\text {rd }}$ month & $6^{\text {th }}$ month \\
\hline$<300$ & 3 & 4 & 7 & 12 & 4 & 5 & 8 & 15 \\
\hline $300-450$ & 13 & 15 & 13 & 8 & 12 & 13 & 11 & 5 \\
\hline$>450$ & 4 & 1 & 0 & 0 & 4 & 2 & 1 & 0 \\
\hline
\end{tabular}

Table 7

From the above table ' $p$ ' value calculated came to be less than 0.0001 which shows it to be extremely significant.

The above data has been compared for central foveal thickness at the end of 6 months between the 2 groups of which:

- $\quad$ First group received macular photocoagulation within 1 week of a single intravitreal bevacizumab injection.
- $\quad$ Second group received photocoagulation in the period beyond 7 days and before 30 days of receiving single intravitreal bevacizumab injection.

The comparision showed that the group receiving deferred photocoagulation had better outcomes as seen by reduced central foveal thickness at the end of 6 month study period as compared to group receiving prompt photocoagulation.

\begin{tabular}{|l|c|c|c|c|c|c|c|c|}
\hline BCVA & \multicolumn{4}{|c|}{ IV A + Prompt MPC } & \multicolumn{4}{c|}{ IV A + Deferred MPC } \\
\hline (In logMAR) & Baseline & $\mathbf{1}^{\text {st }} \mathbf{M}$ & $\mathbf{3}^{\text {rd }} \mathbf{M}$ & $\mathbf{6}^{\text {th }} \mathbf{M}$ & Baseline & $\mathbf{1}^{\text {st }} \mathbf{M}$ & $\mathbf{3}^{\text {rd }} \mathbf{M}$ & $\mathbf{6}^{\text {th }} \mathbf{M}$ \\
\hline$>1$ & 4 & 3 & 3 & 2 & 2 & 2 & 0 & 0 \\
\hline $0.48-0.99$ & 18 & 12 & 12 & 10 & 10 & 9 & 6 & 3 \\
\hline$<0.48$ & 3 & 10 & 10 & 13 & 3 & 4 & 9 & 12 \\
\hline
\end{tabular}

Table 8 
The $\mathrm{p}$ value came to be less than 0.0001 which is significant.

The above data has been compared for outcome in visual acuity at the end of 6 months between the 2 groups of which:

- $\quad$ First group received macular photocoagulation within 1 week of a single intravitreal bevacizumab injection.

- $\quad$ Second group received photocoagulation in the period beyond 7 days and before 30 days of receiving single intravitreal bevacizumab injection.

The comparision showed that the group receiving deferred photocoagulation had better outcomes regarding visual acuity at the end of 6 month study period as compared to group receiving prompt photocoagulation.

\section{Discussion}

- Diabetic macular edema is a pathology which results from leakage due to process of angiogenesis.

- Thus, our aim in the treatment of diabetic macular edema would be to reduce the edema and prevent its further occurrence.

- Hence by injecting intravitreal injection of bevacizumab, the process of angiogenesis is taken care of. It reduces formation of new vessels and thus leakage from them.

- Whereas by laser photocoagulation the already formed leaky vessels are coagulated so that edema from them does not occur.

- It is thus seen that when laser photocoagulation is done within one month of the anti-VEGF injection but greater than 1 week the results obtained are better than laser photocoagulation given within one week of the anti-VEGF injection in terms of visual acuity and central foveal thickness at the completion of 6 months; with a p value that is extremely significant.

\section{Conclusion}

From our study thus it can be concluded that patients receiving deferred macular photocoagulation after a single intravitreal injection of bevacizumab had better outcomes regarding reduction of central foveal thickness and improvement in visual acuity at the end of 6 month observation period compared to those patients receiving prompt macular photocoagulation [1-13].

\section{Bibliography}

1. Gale Jason. "India's Diabetes Epidemic Cuts Down Millions Who Escape Poverty”. Bloomberg (2010).

2. Goldberg MF and Jampol LM. "Knowledge of diabetic retinopathy before and 18 years after the Airlie House Symposium on Treatment of Diabetic Retinopathy". Ophthalmology 94 (1987): 741-746.

3. "Early treatment diabetic retinopathy study research group: photocoagulation for diabetic macular edema: early treatment diabetic retinopathy study report number 9". Ophthalmology 98 (1991): 766-0-785.

4. Yasser M Helmy and Heba R Atta Allah. "Optical coherence tomography classification of diabetic cystoid macular edema”. Clinical Ophthalmology 7 (2013): 10.

5. Asensio-Sánchez VM., et al. "Microalbuminuria and diabetic retinopathy". Archivos de la Sociedad Española de Oftalmología 83.2 (2008): 85.

6. Aksoy S., et al. "Comparison of intravitreal bevacizumab and triamcinolone acetonide theraphies for diffuse diabetic macular edema". International Journal of Ophthalmology 8.3 (2015): 550-555.

7. Arevalo JF., et al. "Primary intravitreal bevacizumab (Avastin) for diabetic macular edema: results from the Pan-American Collaborative Retina Study Group at 6-month follow-up". Ophthalmology 114.4 (2007): 743-750.

8. Takamura Y., et al. "The effect of photocoagulation in ischemic areas to prevent recurrence of diabetic macular edema after intravitreal bevacizumab injection". Investigative Ophthalmology and Visual Science 55.8 (2014): 4741-4746.

9. Heier J., et al. "Comparative Effectiveness Panel. Comparison of Aflibercept, Bevacizumab, and Ranibizumab for Treatment of Diabetic Macular Edema: Extrapolation of Data to Clinical Practice". JAMA Ophthalmology 29 (2015): 1-6.

10. Barteselli G., et al. "Results of the standardised combination therapy for diabetic macular oedema: intravitreal bevacizum$\mathrm{ab}$ and navigated retinal photocoagulation". British Journal of Ophthalmology.

11. Javanović S., et al. "Intravitreal bevacizumab injection alone or combined with macular photocoagulation compared to macular photocoagulation as primary treatment of diabetic macular edema". 72.10 (2015). 
12. Photocoagulation treatment of proliferative diabetic retinopathy. Clinical application of Diabetic Retinopathy Study (DRS) findings, DRS Report Number 8. The Diabetic Retinopathy Study Research Group. Ophthalmology 88.7 (1981): 583-600.

13. Solaiman KA., et al. "Intravitreal bevacizumab and/or macular photocoagulation as a primary treatment for diffuse diabetic macular edema”. Retina 30.10 (2010): 1638-1645.

\section{Assets from publication with us}

- Prompt Acknowledgement after receiving the article

- Thorough Double blinded peer review

- Rapid Publication

- Issue of Publication Certificate

- High visibility of your Published work

Website: www.actascientific.com/

Submit Article: www.actascientific.com/submission.php

Email us: editor@actascientific.com

Contact us: +919182824667 